\title{
Capital and Aesthetics: How Could People’s Freedom be Possible under Modern Conditions? ${ }^{1}$
}

\author{
SONG Wei \\ Northeastern University, Shenyang, China
}

\begin{abstract}
In the age where capital becomes the most dominant, the most manipulating power, the current aesthetics has to face and solve the problems such as “capital versus aesthetics”, "matter nature versus mind nature”, "society versus culture” and has to answer the follow-up question- “How could people’s freedom be possible in modern conditions?” The reflections and criticism on “capital modernity” by Marx, Weber and Simmel all directly pointed to the issues of people's value and the settlement of their spirit in the Age of Capital. Meanwhile, the salvation of the "aesthetic modernity" makes up the proper meaning of the solution in many thinkers' mind to the predicament of the age. In this sense, the reflections on the Zeitgeist in the Age of Capital is certainly included in the pursuit of aesthetic freedom in this age.
\end{abstract}

Keywords: contemporary aesthetics, Marxist aesthetics, capital modernity, aesthetic modernity

If we say philosophy is the Zeitgeist, or the spirit of the age, in understanding theory, then, literature and art are the emotional token of the Zeitgeist. Therefore, a scrutiny into the spirit of the age where we are makes the basic premise and historical context that help understand the current issues of aesthetics. What on earth does the age where we are look like? How should we describe and comprehend the current age? What perspective and footing should we take when we think about "the spiritual situation in the current age"? All these questions lead to a critical issue, that is, the Age of Capital. In whatever sense, we are now exposed to the modernity of capital. Thus, in the age where capital becomes the most dominant, the most manipulating power, the current aesthetics has to face and solve the problems such as "capital versus aesthetics", "matter nature versus mind nature", "society versus culture" and has to answer the follow-up question- "How could people’s freedom be possible under modern conditions?”

\section{The Spiritual Situation of the Age: The Issue of Aesthetics in the Context of Capital Modernity}

Since the new age after the reform and opening up, the Chinese society has gone through a rapidly developing transformation. It is worth mentioning that, during the transitional process from the planned economy

\footnotetext{
${ }^{1}$ Acknowledgements: This paper was funded by the Project of National Social Science Fund of China “A Study on Issues of Capital Modernity and Aesthetic Modernity in Marxist Perspective” (13\&ZD071).

SONG Wei is a Distinguished Professor in the College of Arts, Northeastern University. His research field covers Marxist Aesthetics and Postmodern Theories of Art.
} 
to the market economy, and from the closed economy to the open economy, people's ideas, thoughts, and value orientation, together with their daily life, are all exposed to dramatic changes, consequently, the Zeitgeist has changed drastically, too. Admittedly, it is true that during the transitional social period since the reform and opening up, we have been encountering with the Age of Capital, no matter whether we chose it consciously or unconsciously. Therefore, if we want to find some key words to describe the age properly, we can choose key concepts such as market, commodity, currency, capital, and so on. In other words, in the perspective of modernity, market, commodity, currency, capital have become one of the most dominant and manipulating powers. These concepts can be appreciated and illustrated under the framework of "the modernity of capital". In this sense, the key to exploring the Zeitgeist is how to appreciate and express the modernity of capital, while the key to seeking the modernity of the current aesthetics lies in how to appreciate and express the complex correlation between "the modernity of capital" and "the modernity of aesthetics", which makes the following aesthetics issue prominent in the Age of Capital - How could people's freedom be possible under the modern conditions?

For quite a long time, the lack of understanding and grasping of the real status quo and the cultural spirit of the Age of Capital has been making it hard to explore or to discuss the issue of "art and the age" seriously and deeply. It should be stressed that, due to various kinds of historical and practical reasons, even though we have already thrown ourselves into the modernity of capital, we are still lack of real and sufficient appreciation and grasp of the historical features as well as the inherent spiritual essence of the Age of Capital. Without full awareness of the Age of Capital or theoretical reflection on the modernity of capital, the discussion about the Zeitgeist is bound to be empty talk which is distant from the age. Today, the problem we must face and solve is to see the coming of the Age of Capital, free ourselves from the wrong ideas, and rethink and re-illustrate the general characteristics of the Age with the modernity of capital, which helps find out how the Zeitgeist has been growing and reach theory consciousness to reflect on the current age. Having long been affected by both the ultra-Left trend of thought and materialism in the past years, we have many wrong ideas and taboo areas, or even extreme trend of over illustration in terms of understanding the Age of Capital, as a result of which we have lost our theory consciousness and critical thinking about this Age. As we see, affected by both the ultra-Left trend of thought and materialism, there are two distinct ideas as far as "the modernity of capital" is concerned. One is the "claim of capital as evil", which regards capital as the "root of all evils", and the other is the "claim of capital as omnipotence", which believes capital is an omnipotent power. These two opinions seem opposite to each other. However, both of them have drawbacks of simple or one-sided understanding of either "the modernity of capital" or the Age of Capital.

The "claim of capital as evil" is a typical representation of the ultra-Left trend of thought, which attempts to go beyond the history and exclude all the productive factors related to capital, market and commodity. As a result, it has severely hindered the development of our socialist productivity, leading to a serious stall or regression of the socialist economy and production, which has been far away from the original sense in which it was believed that the socialist system would contribute to the continual improvement of productivity. Affected by the ultra-Left trend of thought, particularly restrained by the planned economic system, we used to regard all the concepts like "capital”, "market”, “commodity”, etc. as capitalist products, and went so far so that we had the ridiculous slogans like "we prefer socialist weeds to capitalist sprouts". In those days, the historical effectiveness of capital allocation on social resources was completely denied, and as the token of capitalist system, capital was thought of as "the root of all evils" and "the top of all evils". 
However, our socialist practice, the new historical practice since reform and opening up in particular, has shown that "claim of capital as evil" was a one-sided wrong idea dominated by the ultra-Left trend of thought. The idea itself and the practice of such a crazy idea resulted in historical disasters, and impeded the construction and development of our socialist country to a large extent. China's socialist practice, especially the historical practice since the reform and opening up, demonstrates that we must get over the one-sided ultra-Left trend of thought as far as capital is concerned. By applying the dialectical method, we should be able to discern the paradox of the existence of capital, seeing both its historical functions, and its historical limitations. We need to understand capital, use capital and control capital, and finally surpass capital, so that we can dialectically solve many problems concerning modernity, such as "capital versus aesthetics", "matter nature versus mind nature", "society versus culture", etc. We should also explore the possibilities to solve and surpass the predicament of modernity or find some alternatives, which help build up the harmonious society where the economic life, political life and cultural life are all coordinated to develop properly.

Similarly, the "claim of capital as omnipotence" is also a one-sided wrong idea, the nature of which is "fetish of money". It adopts the logic that capital manipulates the society completely, and its ultimate goal is to make capital more profitable or more outstretched, turning the society into one where material interest must be maximized to meet the only object of being a "materialized" society. "Money worship" and "materialism" become more and more popular today, which increasingly make people alienated. Social principles of justice and equality are replaced by the principles of profit and capital, the pursuit of the spirit of humanity is stained by the pursuit of material benefit, and morality and ethics were impacted by the paramountcy of money. It must be pointed out that the "claim of capital as omnipotence", whose core is materialism, is an extremely one-sided view and attitude. It also strays away from the development philosophy of "people-oriented" harmonious society that has been constructed by our socialist country. Compared with the "claim of capital as evil", the "claim of capital as omnipotence" goes from one extreme to the other. If we allow this trend to spread continually, there is bound to be major disasters to our socialist cause. Therefore, to the socialist road that China has taken, especially to the construction of the socialist marketing economic system, the issues we are facing and about to solve are undoubtedly as follows: how to see and understand capital, and further, how to use, control, lead and finally surpass capital in order to improve people's material life as well as cultural life.

To the modern aesthetics, it is absolutely of great practical significance today to return to the real historical spot where the modernity of capital arose and to the original context where critique of the capital modernity took place, so that we can understand all over again the great historical significance of why "capital came to this world" as well as the predicament of art's existence in the current age. Marx, Weber and Simmel shared a common vision - with the goal to solve the modernity predicament in the Age of Capital in mind, they put their theoretical thinking into the general problem domain of reflections on and critique of the capital modernity. Marx placed more weight on the economic-philosophical view, revealing the capital logic secret from the historical practice of material production. He pointed out that "capital came to the world" and began to dominate the driving forces of social development as well as the historical regulations. Moreover, he disclosed the phenomena of alienation in the Age of Capital, and tried to work it out, in the hope of finding some political salvation for the sake of human freedom and liberation. Weber paid more attention to the culture view. He measured the validity of value in the modern society with rationalized disenchantment of the modernity process, explored the cultural 
spirit of capitalism in terms of religion and ethics and reconstructed the cultural salvation of the rationalistic value. Simmel started with the aesthetic angle, trying to illustrate modern people's spiritual situation with the thinking of monetary philosophy. From the experience of mind nature, he described the perceptual experience in the Age of Capital in search for the spiritual conversion and cultural salvation of the inner experience. It is true that their analyses were different from one another's, yet they all asked this question: "How could people's freedom be possible under modern conditions?”

\section{The Critique of Capital Modernity: Marx’s Dialectical and Historical Dimension}

Modernity provides a new perspective on studying Marx, which is gradually developed with issues of modernity highlighted in the contemporary world. As a kind of philosophical discourse of modernity, issues of modernity, always centering on the formation and the development of the modern society, are theoretical token of modernity, its theoretical reflection as well as theoretical critique. This undoubtedly determines that issues of modernity are historically specific. In other words, understanding Marx from the perspective of modernity means contextualizing the past interpretation of Marxism, which we see was restricted to theoretical philosophy and ideological philosophy for lack of theoretical modernity perspective. The old interpretation obscured the historical context of Marx's critique of modernity and further weakened the theoretical vitality of Marxist theory on comprehending contemporary issues. As a result, re-illustration of Marx's theory from the perspective of modernity is of great significance to showing critical dimension in the modern society and activating theoretical vitality of Marxism in modern issues.

Generally speaking, the advantages of Marx's modernity critique are mainly reflected in three aspects. One of them lies in the historical dialectics of modernity critique. On the basis of historical materialism, Marx started with the form of material production, scrutinizing the historical process of the formation of modernity, stressing the fundamental role of the modern economic structure of capitalism or the change of the mode of production. Another is the critique of capital modernity. When the study of capitalist modernity is condensed into the realm of the capital modernity, Marx pointed out that the nature of modernity was the capitalist modernity, the core logic of which was modernity of capital. Thus, issues of capital became Marx's major concerns in his scrutiny into modernity. The third is the critique of aesthetic modernity. In the whole process of the critique of capital modernity, Marx always had a hidden structure, that is, the critique of aesthetic modernity, which thus constituted the existential dimension of Marx's critique of modernity.

First of all, historical dialectics of modernity critique. Marx's critique of modernity shows a historical perspective of modernity in a historical dimension, and provides in-depth analysis of capitalist modernity, reaching an unparalleled theoretical level even for the current age. As Heidegger put it, only when standing on such a historical dimension, can one be qualified to start a dialogue with Marx. Undoubtedly, Capitalism is the real historical scenario in which Marx's philosophical change appeared. Capitalism is another name of modernity. The essence of historical process of modernity is the historical process of capital society or capitalism. Only by restoring the real historical scenario when Marx's philosophy came on the stage can we remove Hegel's grandiose narration about historical laws and to show the original image of how Marx established the historical materialism. 
From the outset, Marx had been studying formation of modernity and its characteristics based on the modes of materialistic or economic production, which is different from other general theory of modernity that mainly focused on reflecting modernity from the perspective of rational criticism. This is the very point that highlights significance of the revolutionary change of Marx's theory. Based on historical materialism, Marx started his scrutiny into the historical process of modernity with material production modes, and emphasized the basic function of the change of economic structure of modernity or the change of production modes. He viewed capitalist social formation as a whole, thus confirmed that the center of modernity analysis was modernity of capital. Here we must stress that, though Marx criticized the capitalist modernity relentlessly, he never denied the historic progressive significance of the capitalist development. He always looked critically at dual contradiction or multiple paradox of capital modernity and admitted at the same time the important role the bourgeoisie played in the revolution. As is well known, modernity, or the modern society, was both a brand-new historical process and a complex social and historical process of change. In the whole process, there had been a dramatic transformation in the social, economic, political and cultural structure as well as in daily life, which was quite different from the traditional big change. In the face of this complex historical transformation, Marx interpreted modernity based on the change of modes of material production from the perspective of historical materialism. He acknowledged the basic significance of the change of capitalist production modes and opened a dialectical and historical dimension for the critique of capital modernity.

Second, the critique of capital modernity. Marx condensed his examination of the capitalist modernity into the field of capital modernity, and pointed that the nature of modernity was capital modernity, while the core logic of the capitalist modernity was the capital logic, and thus, the issues of capital modernity became the core proposition in Marx's examination of modernity. The historical context in which Marx criticized modernity was the modern society where the capitalist mode of production dominated. After overturning metaphysics, Marx proposed the "worldization of philosophy" or the "actualization of philosophy", and abandoned the abstract proposition of "staying away from the real world", which had been advocated by the traditional philosophy. Yet the modern society of capitalism is the specific reality that philosophy has to face after its revolutionary change. The disclosure of capital did not only actualize the materiality of philosophical reflection, but also unveil the secrets of metaphysics. By adopting his unique "concrete dialectics", Marx investigated the features of modernity in the given historical period, namely the capitalist modernity. According to the logic of methodology in Das Kapital, goods, currencies and capital are the most common and most representative "concrete abstraction" of modern society. As far as Marx is concerned, the mode of production in capitalistic material life formulates the operation and evolution of the whole history of modernity. Therefore, to investigate and understand the basic features of modernity, the production mode of capitalism must be taken as the starting point. From Marx's point of view, the bourgeoisie, with its power of capital, had created a brand-new modern world based on its own image, and besides, "modern logic" and "capitalist logic" had formed an indispensable and secret conspiracy. Capital, being the "gene" of modern society, does not only contain all the secrets of capitalism, but also conceals that of the modern society. Without understanding of and critiques of the capitalist modernity, the overall critiques of modernity cannot be materialized. Therefore, Marx's critiques of capitalism are actually the critiques of modernity, and his disclosure of capital is that of modern society, which makes the comprehension of capitalist modernity the critical and core topic in the realm of criticism against modernity. The Marxist critiques of 
modernity highlighted the theoretical connotation of modernity. From the perspective of capitalist modernity, given the historical gap between the age of Marx's and that of ours and the consistent development of capitalism, we are still in the age of capitalist globalization today. In this sense, Marx is still with us, and his critiques of and reflections on capitalist modernity are still the most important theories on modernity. Thus, regardless of the reflections on or critiques of modernity, or the reconstruction or termination of it, Marx's theoretical perspective of capitalist modernity cannot be overlooked.

Third, critiques of aesthetic modernity. As regards to the whole process of criticizing the capitalist modernity, there has been a hidden structure, the critique of the modernity of aesthetics, which forms the dimension of existentialism in Marx's critiques towards modernity. The issue of aesthetic modernity touches upon political dimension, value orientation and humanistic care of Marxist critique of modernity. However, for a long time, it should be noted that the issues regarding aesthetic modernity have been neglected or shaded in Marx's critiques of modernity, and the main reason lies in the dogmatic misinterpretation and distortion of "economic determinism" in Marx's historical materialism, which overstates the importance of economic and social structure in modernity, while ignoring the aspects of culture, psychology and aesthetics. Accordingly, the theoretical mode of modernity that is formed in this way is monotonic, and focuses only on the modernity of economy, politics and society, but overlooking that of culture and aesthetics. However, Marx's critique of capitalist modernity is not a kind of economic determinism or reductionism. As far as he is concerned, the secrets of modern times take root in the secrets of capitalist modernity. Similarly, the fate of modern people is hidden in the architecture of capitalist modernity. Therefore, Marx's testification of the capitalist logic of modern society is intended to reveal the complete alienation of humanity, and also to look forward to the vision of overcoming it in the historical development. Though Marx based his analysis on the capitalist economic system, his methods and aims are not limited to the dimension of economics. He always sought to find paths to freedom and liberation, which is in the field of existentialism. That is to say, Marx's theory on modernity embodies both perspectives on political economics of historical materialism, and humanistic care in terms of existentialism, which shows the spirits of dialectical criticism of capitalist modernity with unique significance and value. The complicated historical process indicates that modernity is the historical change on different levels of politics, economy, society, culture and daily life, while various contradictions and paradoxes can be discovered from the inside. In order to confront with and to solve these contradictions and paradoxes of modernity, Marx, in his critiques towards modernity, adopted the strategy of dialectical criticism, which exhibited either duplicity or multiplicity. Among these dimensions, "capital modernity” and "aesthetic modernity” are the most important ones. If "capital modernity" is regarded as the explicit structure of Marxist critiques of modernity, "aesthetic modernity" is its implicit structure. These two structures are both contradictory and complementary. Since the nature of critiques on modernity concerns the question of "the possibility of human freedom in modern times", the absence of cultural modernity or aesthetic modernity would make rootless the ideal of "human freedom and liberation", which Marx aimed to achieve in his critiques of modernity.

\section{The Capitalist Cultural Predicament: Weber's and Simmel's Aesthetic Salvation}

Although Marx's theoretic purport and value was different from Weber's, the general problem domain of the two thinkers were interlinked, namely the capital modernity diagnosis. As Brian Turner emphasized in the 
preface of From Max Weber: Essays in Sociology in the 1991 edition, that we should consider Marx and Weber together as critical analysts for a common modern phenomenon of capitalism, because both of them felt deeply that the momentum of capitalism had broken all the historical and traditional certainty... The result of the rationalization paradox was the emergence of such a world where there existed no sense of authority in a meaningful system. The authoritative rational norms, extraordinary charisma and traditional power were not to be reconciled. Marx saw alienation when analyzing capitalism. Weber put forward a theme regarding modernization as rationalization. As the experts in diagnosing the capital modernity, Marx and Weber came up with the pathological diagnosis of capitalism from different perspectives, and the two thinkers considered the same proposition of the age: "how could people's freedom be possible in the modern age? In this regard, in the book Weber and Marx, LÖwith considered Weber's core issue as the development of humanity in the modern age: although humans could not escape from the capitalist iron cage of rationality, we had the responsibility to face the reality and devote ourselves to the complete development of human nature." ${ }^{1}$ In Weber's view, the spirit and culture of capitalism were presented as the rationalized or reasonable historical process of "the disenchantment of the world”. It is in this very process that the internal tension and conflicts in the value rationality and instrumental rationality became increasingly prominent. The instrumental rationality characterized mainly by calculating, institutionalization and bureaucracy had eventually become the dominant power to determine one's destiny in modern society. The so called instrumental rationality refers to the ability to achieve the goal of efficiency and utilitarianism based on calm and objective calculation and planning, while the value rationality refers to the ability to achieve the value purpose by sticking to the subjective will and wishes, together with ideal and faith. The greatest difference between the instrumental rationality and the value rationality was that the instrumental rationality focused on the possibility and necessity of implementation of a means. As long as the means had gone through calculation and planning and the whole process and procedures were reasonable, the act itself would be considered rational and it was bound to achieve efficiency and maximize utility. The absolute manipulation of the instrumental rationality ignored the value concern of the value rationality, resulting in rupture and conflict between the two. According to Weber, unlike the instrumental rationality which only took calculation and planning into account, and abandoned value and belief, the value rationality paid more attention to value and belief. However, the actors of value rationality thought that with some belief and sense of responsibility in mind, they should make every effort to achieve their ideal and fulfill their hope by fair means or foul. As long as the ideal or hope was good, the action taken on the basis of the ideal or hope should be considered rational. So, similarly, there existed hidden danger that the goal justified the means in the impulse of rationality, that is to say, irrational factors were hidden in the value rationality itself, or, even the value rationality itself was a kind of irrational existence. At this point, it was difficult to resolve the predicament of modern society, and the paradox of rationality and freedom became a problem of modernity that puzzled Weber.

Faced with disintegrating modernity and fragmentary spiritual conditions in the current age, Weber had been seeking a modern approach to salvation, trying to fill the value vacuum of the moral belief, emotional taste and happiness of life caused by "disenchantment of the world" so as to solve the problem of modern development in terms of rationality, freedom and human. Based on the attitude of value neutrality in academic research, Weber

\footnotetext{
${ }^{1}$ Karl LÖwith, Max Weber and Karl Marx, New York: Routledge, 2003. p. 20.
} 
tried to avoid excessive expression of the value position, instead, he focused on the description of the rationalized process of capitalism and "How it makes us what we are like now". He was always concerned with cultural and spiritual salvations of the modern society, trying to break through the "iron cage of rationality" weaved by modernity and seek the possibility for the development of human freedom. Among different kinds of salvation, the religious ethics salvation and the aesthetic salvation were conceived as the possible path to save the scattered and collapsed modern world. For religious ethics salvation and aesthetic salvation, Weber placed more emphasis on exploring the cultural spirit of capitalism from the religious ethics level, trying to rebuild the salvation of religious ethics with value rationality, but he also saw salvation of cultural function that lied in art and aesthetics. Admittedly, when it came to how to deal with the issues of religious ethics salvation and aesthetic salvation, Weber's attitude was very cautious or not optimistic, which at least could not compare with the later Frankfurt School that excessively depended on the salvation of aesthetic utopia. In spite of this, Weber addressed the issue of aesthetic salvation in a limited space. He pointed out that wizardry religious piety had the closest link to the aesthetic field, because for aesthetic creation and for the stylized tradition, religion was an inexhaustible source of opportunity at the outset...In terms of art, as long as a creative artist experienced in person that his achievements were produced from skills (originally thought of as witchcraft), charisma or initiative activities, the relation between religious ethics and art would always remain in a state of harmony. However, the development of intellectualists and rationalization of life changed it. The reason was that, under such conditions, art became a system that grasped the independent values with increasing consciousness, while the existence of these values was well-deserved. Art took over the function of salvation in this mortal world. As to how to explain it, it does not really matter. It offered salvation from the rituals of daily life, especially from under the stress of the rationalism growing day by day between theory and practice. As we see, social system with modernity was a highly organized process in society that was constructed by means of rationalization and legalization. Since entering the history of modernity, enlightenment rationality has completed the disenchantment of religious myth, so that the society built upon the integration of ethical and religious values began to fall apart, the wizardry culture built in pre-modern society was decomposed by rationality into instrumental rationality, and the function of art changed from worship value to display value. The mystic charm of culture and the aura and glow of art gradually disappeared into scattered pieces. During the rationalized process of disenchantment, art was split apart from the wizardry culture into two aspects: on the one hand, it became remainders of wizardry culture; on the other hand, it became self-disciplined culture undertaking the function of aesthetic salvation value; and from then on, it opened a long road of aesthetic salvation.

Simmel's analysis and critique of capital modernity also focused on the issue of the age as to "how the freedom of man could be possible" in the conditions of capitalist society. The difference was that, Simmel was more devoted to inner mind feeling experience, that is, people's inner spirit changes brought about by the Age of Capital, thus presenting a distinct aesthetic fashion and color of humanistic solicitude. In The Philosophy of Money, Simmel clarifies that Marx’s Das Kapital did not really address what he cared about: the issues of monetary philosophy. For that reason, starting with where Marx has not begun or ended, he began to think about the close connections between currency versus culture value, currency versus life experiences, and the currency versus spiritual life. Quite the same as the relationship between Marx and Weber, Marx and Simmel were both the pathologists who diagnosed the capital modernity. It is noteworthy that Simmel and Marx both saw the paradox 
between capital and currency. Simmel believed that the torrent of modern culture rushed into two opposite directions: on the one hand, it connected the most distant things together, tending to sweep away and level conflicts, so as to produce a more and more tolerant social stratum. On the other hand, it tended to emphasize the most individual things and favor individuality and the autonomy of development. Monetary economy supported the two directions at the same time. For one thing, it made possible the interest media, connection media, and understanding instruments that were very general, equally effective everywhere; for another, it also had the biggest leeway for the maximum of individuality, making the individualization and freedom possible. In Simmel's opinion, currency or capital was a kind of tremendously powerful existence that were "impersonal", "featureless" and "colorless". So, the world under the control of currency or under the manipulation of capital was doomed to be more and more deficient and void; it was because of this deficiency and void that modern people sank into the dilemma full of paradoxes.

Obviously, Simmel tended to prefer the latter, in regard to society versus individual, subjectivity versus objectivity, rationality versus freedom, means versus purpose, homogeneity versus mobility, and calculating versus passion. He cherished the hope that aesthetics would take the responsibility to rescue the turbulent modern world from peril. In Simmel's eyes, currency, money and commodities had already become the rules of dialogue in modern society. He believed that "the modern-style rationalism was apparently affected by the monetary system." ${ }^{2}$ In an Age of Capital where monetization was overwhelming, the nature of mind and spirits of humanity were increasingly computerized, formatted, rationalized, and objectified. In the process of monetary homogenization, people changed their way of experiencing the nature of mind and the feeling from the inner heart, and the modern people's spirit and soul were more and more concerned with calculation. The rationalist style dominated by the influence of the monetary system became a cultural token of this modern world. The modern society reversed the order of means and purpose, and the magic of money, the charm of commodity and the logic of capital turn out to be the predominant power in society. Capital, by all means, was an instrument, a form, a tool; it was nothing but a bridge that led to man's own destination. However, man could not live on the bridge. As Simmel put it, money was merely a bridge leading to our ultimate values, and the bridge was not man's habitat. In the process of logic homogenization, currency turned into a universal medium, or quid pro quo, which could be calculated and exchanged. With these features, it was able to remove all the differences of value, making it possible not only to exchange objects for objects, but also to exchange people for people. It was so powerful that it sucked everything including mind, emotions, feelings and experiences, etc. into the all-encompassing scale of monetary calculation. Hence, the previous glorious spirit and noble soul were both converged into "the vast sea of money”, and the ulterior inner world was formatted by the monetary calculation. The "aura" of perceptual aesthetics was evaporated. Modern people degenerated into fragmented being; the Zeitgeist became a homeless ghost. Under the force of such common monetary medium, modern men did not use their mind to think, instead, they used their brains. The entire world turned into the objects of quantification, and all doubts and puzzles about life could be transmuted into mathematical questions. In response, Simmel deplored that, though we could not assert that the Zeitgeist in our age was already stuck in such a state, it was approaching that state. Apparently, in his eyes, the capital logic was totally incompatible with the poetic aesthetics. In the modern Age of Capital,

\footnotetext{
${ }^{2}$ Georg Simmel, Money, Sex and Modern Mode of Life (Chinese version). East China Normal University Press, 2010, p. 2.
} 
aesthetic feelings faded away and the "aura" of art died away, thus an individual with pure aesthetic mentality would feel desperate about the modern world. Thus, Simmel lamented the decadency of the aesthetic world that used to be characterized by an experience of the nature of mind, expecting the modern people to return to their spiritual garden in the poetic existence of artistic aesthetics. But the massive power of monetary capital—which was "impersonal", "featureless" and "colorless"-stroke him, and his expectation plunged into boundless sadness and despair. Simmel distinguished himself from others with his perceptual artistic aesthetic review on the modernity of capital from the angle of experiencing mind. He then presented an aesthetic and perceptual perspective from which the future generations would perceive the dimensions of the Age of Capital, and explored a way in which we would resist the unidirectional evolution of the alienation in a society of capital so as to seek an aesthetic utopia of perceptual liberation.

To summarize, the reflections and criticism on capital modernity by Marx, Weber and Simmel all directly addressed the issues about modern people's living situation. Through the analysis of the Age of Capital, they sought the answer to "the possibility of people's freedom in the modern conditions" and inquired into the proposition of this age-how to settle down and get on with one's pursuit. Caring for humans under the conditions of modern mode, these three great thinkers' concerns all pointed to the issues of people's value and the settlement of their spirit in the Age of Capital. Meanwhile, the salvation of the aesthetic modernity, together with the salvation of the cultural modernity, makes up the proper meaning of the solution to the predicament of the age. In this sense, the reflections and criticism of the Age of Capital evidently bear the features of humanistic concern, while the reflections on the Zeitgeist in the Age of Capital is certainly included in the pursuit of aesthetic freedom in this age.

Historically, aesthetic modernity had long been the strategy for the western intellectuals to resist capitalism. They hoped to fight against the alienated society by the utopian imagination of artistic aesthetics. However, too much hope on the aesthetic imagination usually fell down to the utopian illusion, which lacked the real strength to change the reality. As early as the German classic aesthetic period, Kant, Schiller and Hagel and a large number of other thinkers were already aware of the great importance of what aesthetics meant to the realization of the modern people's freedom. They tried to compensate the one-sided and unbalanced development of the material dimension with the aesthetic dimension, so as to change the materialized situation of modern capitalist society. The western Marxists perpetually devoted to the structure of aesthetic Utopia firmly believed that aesthetics would help to answer the question of the age-how to make people's freedom possible under the modern conditions. By inheriting their pursuit of "aesthetic modernity" of these classic German aesthetics, Marx was able to come up with the vision of the communist ideals with the consistent hidden pursuit of aesthetic modernity, which helped define an ideal human society of socialism and communism totally different from capitalism. If we say the issue of "capital modernity" relates more to the modernization of material production, well, the issue of "aesthetic modernity" directly relates to the modernization of people’s spiritual production. Capitalist society made a one way development of the "capital modernity", which caused modern society more and more like a "cage of unidirection”. The material richness didn't change the phenomenon of human alienation, instead, it made people's pursuit for value stuck to the historical wildness of "nihilism”, leaving modern people adrift and homeless. Artistic aesthetics is concerned with the construction of human psychic structure, the nature of which is to establish harmonious society to make people's completely free development possible. In this sense, aesthetic 
modernity directly concerns how to understand the fundamental concepts of "people-oriented", "harmonious society" about the Chinese socialism. It also concerns how to take a road of socialist modernity which is different from the capitalist one. Hence, we need to think about how to dialectically interpret the "capital modernity" and "aesthetic modernity" in the Marxist perspective, and how to dialectically solve the paradox between the "capital modernity" and the "aesthetic modernity" in the socialist practice in order to build up a "people-oriented harmonious society" with the Chinese characteristics? The answers to these questions of the age are yet to be constantly sought and concerned.

\section{References}

Karl LÖwith. (2003). Max Weber and Karl Marx. New York: Routledge.

Georg Simmel. (2010) Money, Sex and Modern Mode of Life (Chinese version). East China Normal University Press. 